\title{
Reply to: 464_126 (2008: 22(12) 2763-2764) Re: Transvaginal laparoscopic cholecystectomy
}

\author{
Marc Bessler · Peter Stevens • Luca Milone • \\ Andrew Gumbs $\cdot$ Dennis Fowler
}

Published online: 15 January 2009

(C) Springer Science+Business Media, LLC 2009

We thank Dr. Alessiani for his comments and congratulate him for the excellent work done on NOTES in the animal lab.

NOTES techniques are in evolution; investigators from all over the world are working on NOTES procedures [1, 2]. We agree that nomenclature is important in communicating about these techniques and believe that if dissection is primarily performed with laparoscopic instruments, then the procedure is laparoscopy.

After working in the animal lab, we acquired the necessary skills and experience to translate our work into human NOTES surgery [3].

We are happy that more groups are embracing this interesting technique and we encourage work such as yours in the animal lab before proceeding to the human operating room.

\section{References}

1. Bessler M, Stevens DP, Milone L, Hogle N, Durak E, Fowler D (2008) Multimedia article: transvaginal laparoscopic cholecystectomy: laparoscopically assisted. Surg Endosc 22(7):1715-1716

2. Pai RD, Fong DG, Bundga ME, Odze RD, Rattner DW, Thompson CC (2006) Transcolonic endoscopic cholecystectomy: a NOTES survival study in a porcine model (with video). Gastrointest Endosc 64(3):428-434

3. Bessler M, Stevens PD, Milone L, Parikh M, Fowler D (2007) Transvaginal laparoscopically-assisted, endoscopic cholecystectomy: a hybrid approach to natural orifice surgery. Gastrointest Endosc 66(6):1243-1245
M. Bessler $(\bowtie)$

Department of Surgery, Columbia University College of Physicians and Surgeons, New York, USA

e-mail: mb28@columbia.edu

\section{P. Stevens}

Department of Medicine, Division of Digestive and Liver Disease, Columbia University College of Physicians and Surgeons, New York, USA

\section{Milone}

Department of Surgery, Columbia University Medical Center, New York, USA

e-mail:1m2440@columbia.edu

\section{A. Gumbs}

Department of Surgical Oncology, Fox Chase Cancer Center, Philadelphia 19027, USA

D. Fowler

Columbia University College of Physicians and Surgeons, New

York, USA 